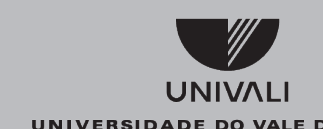

UNIVERSIDADE DO VALE DO ITAJAÍ

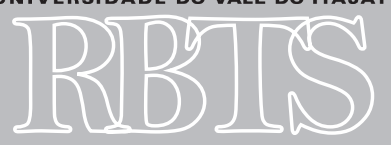

Revista Brasileira de Tecnologias Sociais
1 Universidade do Vale do Itajaí. Núcleo de Telessaúde de Santa Catarina. E-mail: marcos. aurelio@univali.br

2 Universidade do Vale do Itajaí. E-mail: felipemarcolini@ hotmail.com

3 Universidade do Vale do Itajaí. E-mail: julianoloblein@ hotmail.com

4 Universidade Federal de Santa Catarina. Núcleo de Telessaúde de Santa Catarina. E-mail: luiseludke@gmail.com

5 Universidade Federal de Santa Catarina. Núcleo de Telessaúde de Santa Catarina. E-mail: luanagnilson@gmail.com_

$\underline{6}$ Universidade do Vale do Itajaí. E-mail: claricemunaro@hotmail. com

7 Universidade Federal de Santa Catarina. | E-mail: lu.cutolo@ gmail.com
Revista Brasileira de Teonologias Sociais, v.3, n.2, 2016

doi: $10.14210 /$ rbts.k3.n1.p23-36

\section{Participação social na saúde no Brasil - revisão integrativa}

\author{
Social participation in health in Brazil - an \\ integrative review
}

\author{
MARCOS AURELIO MAEYAMA ${ }^{1 ;}$ FELIPE MARCOLINI DANTAS \\ BERTUCCI $^{2 ;}$ JULIANO DE PAULA LOBLEIN ${ }^{3 ;}$ LUÍSE LUDKE DOLNY; $^{4 ;}$ \\ LUANA GABRIELE NILSON ${ }^{5 ;}$ CLARICE APARECIDA MUNARO $^{6}$ LUIZ $^{\text {L }}$ \\ ROBERTO AGEA CUTOLO
}

RESUMO: Este artigo discute a participação social no âmbito do Sistema Único de Saúde, em especial os conselhos de saúde, tendo como referência a construção da democracia participativa, como forma ampla de direito à cidadania. Foi realizada revisão integrativa de 147 artigos e utilizados 55 para este estudo. $\mathrm{O}$ material passou por análise de conteúdo temático e apresentou como resultado quatro grandes categorias relacionadas à participação social: conceitos e contexto da participação, empoderamento, representação e representatividade. A pesquisa conclui que em todas as categorias analisadas existe grande distorção de seus sentidos e propósitos, necessitando de ampla discussão e ações para seu desenvolvimento e consolidação, para a garantia do exercício da cidadania.

Palavras-chave: Participação Social. Conselhos de Saúde. Sistema Único de Saúde.

ABSTRACT: This article addresses social participation in the National Health System, in particular, the Healthcare Councils, with reference to the construction of a participatory democracy, as a broad form of the right to citizenship. An integrative review was carried out, resulting in 147 articles, of which 55 articles were selected and used in this study. The material was analyzed through thematic content analysis, resulting in four main categories related to social participation: concepts and context of social participation, empowerment, representation and representativeness. The research concludes that in all the analyzed categories, there is considerable distortion of the meanings and purposes of social participating, demanding an in-depth discussion, and actions for its development and consolidation in order to guarantee the exercise of citizenship.

Keywords: Social Participation; Unified Health System; Health Councils; Democracy. 
UNIVALI

UNIVERSIDADE DO VALE DO ITAJAÍ

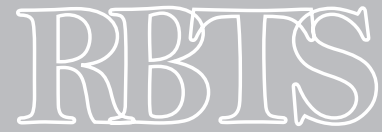

Revista Brasileira de Tecnologias Sociais 


\section{INTRODUÇÃO}

Após o fim da ditadura e a elaboração da Constituição de 1988, inaugura-se no Brasil um modelo de democracia que combina a representação com a participação direta (MOREIRA; HEIDRICH, 2012).

A democracia representativa é a forma tradicional de eleição político-partidária na qual a população elege seus representantes legislativos e executivos. Porém, ainda que democrática, a participação do cidadão se dá apenas no momento do voto, reduzindo sua soberania nas decisões sobre as políticas públicas (SIPIONI; SILVA, 2013).

Já na democracia participativa, os próprios cidadãos da sociedade civil deliberam sobre assuntos de interesse coletivo, especialmente relacionado às políticas públicas, controlando as ações do Estado (MOREIRA; HEIDRICH, 2012).

O processo de democratização na saúde se inicia com a Constituição Federal de 1988, que aponta a participação social com um dos princípios doutrinários do novo sistema de saúde (BRASIL, 1988), a qual foi posteriormente regulamentada, com a publicação da Lei nº 8142/90, que estabelecia a participação social por meio das Conferências de Saúde e dos Conselhos de Saúde, abertos aos membros da sociedade civil nas três esferas de governo (BRASIL, 1990).

A participação social, mais que um direito, passa a ser entendida como requisito indispensável para a viabilidade e a efetividade das políticas públicas (BUSS, 2000), uma vez que os mecanismos tradicionais de democracia representativa não conseguiam garantir a efetividade desse processo (MENDES, 2007), com grande distanciamento da vontade dos representados (MILANI, 2008).

Os conselhos gestores têm sido considerados como modelo que mais se aproxima do ideal da democracia participativa. Ainda que prescinda e se materialize pela forma de representação, as decisões são discutidas pela sociedade civil (MAGNAGNAGNO; DOMBROWKI, 2011).

Nos conselhos gestores, a população em parceria como Estado assume a corresponsabilidade pela definição das políticas de saúde, bem como o monitoramento de todo o processo de execução.

Inúmeras evidências também têm demonstrado que apenas a existência formal dos espaços de deliberação social não assegura a participação da sociedade. Os conselhos de saúde, em maior ou menor grau, apresentam uma série de problemas que compromete sua eficácia e, consequentemente, a efetiva participação social (WENDHAUSEN; CAPONI, 2002).

Neste contexto, o estudo teve como objetivo realizar uma análise da participação social no Sistema Único de Saúde (SUS), destacando o papel dos Conselhos Municipais de Saúde (CMS) nesse processo.

\section{METODOLOGIA}

O presente estudo caracteriza-se como uma revisão integrativa, uma modalidade de produção científica, a qual inclui a análise de pesquisas relevantes que dão suporte para a tomada de decisão sobre um determinado tema, possibilitando a síntese do estado do conhecimento (POLIT; BECK, 2006).

Diferente da revisão sistemática, que busca de forma rigorosa, em bases de dados específicas, todas as pesquisas ou estudos experimentais relacionados ao tema, a revisão integrativa 
permite a inclusão de literaturas teórica e empírica que colaborem para a melhor compreensão do fenômeno (SOUZA; SILVA; CARVALHO, 2010).

A variedade na composição da amostra da revisão integrativa em conjunção com a multiplicidade de finalidades deste método proporciona como resultado um quadro completo de conceitos complexos, de teorias ou problemas relativos ao assunto abordado (BROOME, 2000).

A busca pelas publicações foi realizada na biblioteca virtual Scientific Electronic Library On-line, Biblioteca Virtual em Saúde, base de dados da Literatura Latino-Americano e do Caribe em Ciências da Saúde, e Google Acadêmico, mediante associação simples de Descritores em Ciências da Saúde: Participação Social; Participação Comunitária; Conselhos de Saúde; Sistema Único de Saúde.

Ao total, foram eleitos e lidos 147 artigos compreendidos entre 1979 e 2015, sendo destes utilizados nesta revisão um total de 47 artigos. Para eleição dos artigos, foram analisados os resumos dos trabalhos e incluídos os que discutiam a participação social. Os artigos incluídos sofreram leitura exaustiva e análise crítica, e foram separadas unidades de registro que discutiam a participação como expressão do controle da sociedade civil sobre as políticas de saúde. Posteriormente, as unidades de registro foram agrupadas em categorias temáticas e organizadas em forma de síntese (MINAYO, 2007).

\section{RESULTADOS E DISCUSSÃO}

A revisão de literatura sobre a participação social em conselhos gestores de saúde demonstrou quatro grandes categorias relacionadas ao tema: conceitos e contexto da participação social; empoderamento; representação na democracia participativa; e representatividade.

\subsection{Conceitos e Contexto da Participação Social}

A expressão participação social designa um espectro variado de ações, resultantes da influência da sociedade civil em questões relacionadas com a organização social e que, desta forma, agregam o conjunto de sentidos sobre participação (ACIOLI, 2005) a seguir descritos.

O conceito de controle social é ambíguo, uma vez que pode ser concebido em diferentes sentidos, dependendo da organização do Estado e da sua relação com a Sociedade. Tanto é empregado para designar o controle do Estado sobre a sociedade, quanto para designar o controle da sociedade (ou de setores organizados da sociedade) sobre as ações do Estado (CORREIA, 2005). Este último sentido aproxima-se da definição de participação popular, que enfatiza a expressão política de grupos representativos da sociedade civil na definição de políticas públicas em espaços participativos (ACIOLI, 2005).

Já o termo participação comunitária remete à busca de melhoria das condições de vida da população de uma determinada localidade, as quais com recursos próprios utilizam sua força para dotar a comunidade de um bem que o Estado, até então, não conseguiu garantir (ACIOLI, 2005).

No âmbito do SUS, a participação social foi concebida na perspectiva de que os setores organizados da sociedade participem da definição, da formulação e do acompanhamento da execução das políticas públicas. Portanto, reconhece o direito da população de participar das decisões que afetam sua vida cotidiana e promove a democratização para o controle social das instituições (VÁZQUEZ et al., 2002), desta forma, relacionadas conceitualmente à participação popular. 
Segundo Patemann (1992), a participação desenvolve atitudes de cooperação, integração e comprometimento com as decisões, bem como aumenta o senso de eficácia política. Apesar de ressaltar que a maioria dos cidadãos não está preocupada com decisões da política nacional, acredita que sem experiências participativas em outras esferas da sociedade, não é possível gerar um governo democrático.

A participação social (popular) só é plena quando a sociedade civil e o Estado não se constituem de partes antagônicas, isto é, quando o Estado deixa de tutelar a sociedade e quando os cidadãos de posse de seus direitos passam a militar ativamente em todos os setores que afetam direta ou indiretamente suas vidas, garantindo assim conquistas verdadeiras da sociedade (BRASIL, 1986).

No âmbito do SUS, os conselhos de saúde representam a forma institucionalizada e permanente da participação social, garantida por lei, com caráter deliberativo, e composição paritária entre os representantes da sociedade civil e demais representações (BRASIL, 1990). A garantia legal e a condicionalidade de formalização dos conselhos de saúde para repasse de recursos fundo a fundo garantiram que estes espaços fossem criados, porém o que se verificou foi que a sociedade civil não se encontrava preparada para a participação social (PRESOTO; WESTPHAL, $2005)$ e, na maioria dos municípios, sua criação foi mera formalidade, sem mobilização da sociedade civil e sem construção de gestão participativa (VAN STRALEN et al., 2006).

Além disso, a participação social nos conselhos pode ser bastante duvidosa, uma vez que a desigualdade no acesso à informação da população (e de seus representantes) e sua dificuldade de organização limitam a possibilidade de influenciar o governo na condução das políticas públicas, reforçando as desigualdades já existentes (POZZONI, 2002).

A condução da presidência dos Conselhos Municipais de Saúde (CMS) pelos secretários municipais de saúde (VAN STRALEN et al., 2006) e a irregularidade na periodicidade das reuniões também são fatores limitantes para a efetiva participação social (COTTA; CAZAL; MARTINS, 2010).

Observa-se ainda que, em geral, a pauta das reuniões dos CMS é predeterminada pela representação governamental ou por prestadores de serviço, sendo que dificilmente algum assunto é proposto pelos profissionais de saúde e, menos ainda, pelos usuários. A definição dos temas da pauta é um dos aspectos mais importantes para a participação social, uma vez que, se definida pelas bases da população, a discussão se dá a partir de suas necessidades (WENDHAUSEN; CARDOSO, 2007).

Em alguns conselhos, existe ainda uma grande subordinação por parte dos conselheiros para as decisões tomadas pelo gestor municipal, muito devido à falta de informação e conhecimento sobre as políticas de saúde e do próprio desconhecimento sobre o funcionamento dos conselhos por parte dos usuários e ainda muitas vezes corroboradas pelo uso de linguagem técnica (SILVA, 2007).

A criação de conselhos gestores participativos ainda carrega o legado de uma cultura política autoritária e hierárquica, com grande dificuldade por parte dos governos de compartilhar o poder, realizando composição com aliados políticos da sociedade civil e restringindo assim o potencial democrático desses espaços (COELHO, 2007).

O receio do controle pela sociedade das políticas de saúde faz com que o gestor municipal negligencie sua importância e desenvolvimento, especialmente por meio do acesso às informações, gerando nos espaços instituídos de participação um cenário de disputas político-partidárias e corporativas, ficando a discussão e o fortalecimento das políticas de saúde em segundo plano (CONASEMS, 2009). 
Ao contrário do receio de divisão de poderes, o gestor municipal deve compreender que a participação efetiva da sociedade civil nas decisões compartilha responsabilidades, legitima as ações de saúde, além de fortalecer a política pública de saúde frente a outros setores (CONASEMS, 2009).

Além disso, a participação pode significar uma melhor qualidade nos serviços prestados, uma vez que atende às necessidades expressas pelas pessoas e não simplesmente o que gestores ou profissionais atribuem ser o correto, tornando assim as políticas públicas mais eficazes (CUNILL GRAU, 2004).

Este cenário que pouco atende as necessidades da população, que não realiza o empoderamento do segmento dos usuários e que mecaniza seu funcionamento faz com que a participação social se esvazie nos conselhos (SHIMIZU et al., 2013). Do contrário, o que pode influenciar a participação da população nestes espaços é a demonstração de que sua voz de fato tem influência na condução das políticas, com repercussão na sua vida cotidiana (ABERS, 2001).

\subsection{EMPODERAMENTO}

A categoria empoderamento tem sido utilizada em três dimensões distintas: no nível organizacional, no nível individual e no nível comunitário (BAQUERO, 2012). Neste estudo, que trata especificamente do setor público, interessa o empoderamento no nível individual e comunitário.

O empoderamento individual diz respeito à capacidade de as pessoas assumirem o controle para a melhoria de sua condição de vida, porém, ainda que esteja ligado às habilidades pessoais, depende da interação do indivíduo com seu meio social (BAQUERO, 2012). Já o empoderamento comunitário está relacionado com o processo de capacitação de grupos ou comunidades para agirem de forma participativa e coletiva, influenciando o Estado para a conquista de seus direitos de cidadania (BAQUERO, 2012).

Para Freire e Shor (1986), não existe dimensão individual do empoderamento, uma vez que o processo é relacional, acontece na interação entre indivíduos, na busca de uma mudança da realidade para a transformação social. Neste sentido, o empoderamento situa-se numa perspectiva de autonomia de indivíduos e comunidades, com possibilidade de voz, influência e capacidade para decisão e ação (HOROCHOVSKI; MEIRELLES, 2007).

O empoderamento não se dá ou se transfere para pessoas ou grupos, pois se trata de processo autônomo. Porém agentes externos podem favorecer a criação de espaços e de situações que o desenvolvam (KLEBA; WENDHAUSEN, 2009), especialmente pelo fato de muitas vezes os sujeitos não empoderados estarem em situação de desvantagem ou exclusão social e que, de forma espontânea, dificilmente conseguirão os recursos necessários para mudança da realidade (HOROCHOVSKI; MEIRELLES, 2007).

A equipe de saúde pode e deve desempenhar papel de mediação entre a comunidade/ sociedade civil e as instâncias governamentais e de gestão, exercendo papel de/em defesa dos primeiros, no sentido do empoderamento individual e comunitário (BAQUERO, 2012).

O empoderamento como fim tem o objetivo de promover a redistribuição do poder e a inclusão social, assumindo, desta forma, a relação com a equidade e a justiça social. Já o meio para tal situa-se na dimensão educativa como prática dialógica e contextualizada, ou seja, parte da práxis dos indivíduos, num movimento contínuo de ação-reflexão-ação (FREIRE, 2004). 
Além disso, estratégias de socialização de informações, educação para a cidadania, experiência em processos participativos de tomada de decisão e projetos sociais também podem fomentar o empoderamento (MARTINS et al., 2009).

Neste sentido, Navarrete et al. (2003) destacam os CMS, pela sua capacidade de tomada de decisões, como sendo a principal forma institucionalizada de empoderamento popular. Porém alertam que sua forma de organização e funcionamento acabam levando a baixa adesão da população.

Como consequência, na maioria dos municípios, os conselhos têm se mostrado apenas como uma realidade jurídica-formal, sendo na grande parte das vezes um instrumento monopolizado nas mãos de prefeitos e das elites falando em nome da comunidade (GOHN, 2002).

Para que ocorra uma mudança neste cenário, Gohn (2002) reforça a importância da proximidade dos representantes com os usuários. A publicização das decisões tomadas é fundamental, porque indica comprometimento e responsabilidade dos conselhos, além de assegurar a confiabilidade nos mecanismos participativos e cumprir com o papel educativo junto à população, pois mostra a possibilidade da real efetivação do controle social na gestão compartilhada de políticas públicas.

Neste sentido, Wendhausen e Cardoso (2007) e Correia (2005) ressaltam que, para alcançar legitimidade, os sujeitos devem ter educação/conhecimento em democracia participativa, e que esta somente seria alcançada por meio da participação na prática dos cidadãos nos processos decisórios. Em consequência, para que exista uma forma de governo democrático, é necessária a máxima participação da sociedade, pois ela tem um efeito integrativo e ajuda o indivíduo a aceitar as decisões coletivas, e o torna melhor capacitado para a participação, desenvolvendo virtudes democráticas e coletivas.

Assim, segundo Carvalho e Santos (1992), a força social capaz de mudar a política de Estado só acontece com a consciência social, politização e ampla mobilização, incluindo os trabalhadores, bem como a sociedade civil de modo geral.

\subsection{REPRESENTAÇÃO NA DEMOCRACIA PARTICIPATIVA}

Representação significa “fazer as vezes do outro” em um determinado momento ou espaço. Mesmo nos espaços participativos, a representação se faz necessária no âmbito da política, seja por uma questão de impossibilidade de participação do indivíduo ou mesmo por uma questão de escala, e por isso delegam esta tarefa a um representante (SERAFIM; SANTOS, 2008).

Ainda que a participação da sociedade civil seja a forma mais ampla e desejada de democracia, ela prescinde de formas de representação para sua materialização (MENDES, 2007).

Na democracia participativa, a escolha do representante é feita entre os próprios atores da sociedade civil, o que já garante relativa identificação com o grupo (AVRITZER, 2007), podendo ser escolhido por eleição, indicação ou consenso entre os pares (SERAFIM; SANTOS, 2008).

Neste tipo de representação, devem ser criadas afinidades intermediárias, pois mesmo em um grupo associativo ou comunitário, existem interesses distintos, cuja solidariedade e interesses parciais devem prevalecer (AVRITZER, 2007). Tais afinidades são chamadas por Young (2006) de perspectivas sociais, que superam a ideia de opiniões e interesses, e por meio do processo democrático comunicativo visam ao estabelecimento da justiça. 
Representação é, portanto, uma relação de confiança, controle, prestação de contas e autonomia entre representantes e representados, e por se dar dentro da política, vai depender de uma correlação de forças e vontades que se entrelaçam nos espaços de debate e deliberação (SERAFIN; SANTOS, 2008).

A participação social na saúde se dá por meio de representação de segmentos da sociedade civil em espaços institucionalizados, como os conselhos e as conferências (SERAFIN; SANTOS, 2008).

Os CMS, pelo seu caráter permanente e local, têm sido considerados elementos primordiais no processo de construção da cidadania e controle pela sociedade (MARTINS et al., 2008) e, para tanto, tornam-se fundamentais o papel e a composição da representação dos usuários.

A legislação garante a paridade da representação da sociedade civil nos conselhos, nas três esferas de governo, destinando 50\% para este segmento, e o restante distribuído entre trabalhadores da saúde (25\%), e gestores e prestadores de serviços (25\%) (BRASIL, 1990).

Um estudo realizado por Cotta, Cazal e Martins (2010) demonstrou que existe o respeito aos $50 \%$ destinados ao segmento da sociedade civil na composição dos conselhos, porém o segmento de gestores totalizava $22,7 \%$, prestadores de serviço $18,2 \%$ e apenas $9 \%$ destinado aos profissionais da saúde, o que poderia tornar o processo decisório, de certa forma, tendencioso.

Além disso, é importante, por uma questão ética, não ter entre o segmento dos usuários pessoas que potencialmente possam ter conflito de interesses ligados a outros segmentos representativos dos conselhos de saúde (gestão, prestadores de serviço ou profissionais de saúde) (CONASEMS, 2009).

De acordo com a Resolução no 453/2012, do Conselho Nacional de Saúde, a representação dos usuários poderá ser composta por entidades, instituições e movimentos representativos da sociedade civil, incluindo: associações de pessoas com patologias ou deficiências; entidades indígenas; movimentos sociais e populares organizados; entidades de aposentados e pensionistas; entidades de sindicatos e de trabalhadores; entidades de defesa do consumidor; organização de moradores; entidades ambientalistas; organizações religiosas; entre outras. Não havendo segmentos organizados da sociedade civil para compor o conselho, o mesmo deverá realizar em plenária, de forma democrática, outras formas de organização que representem a sociedade civil (BRASIL, 2012), sendo que a decisão de composição deve respeitar principalmente a vontade da população, a fim de garantir legitimidade (SHIMIZU et al., 2013).

Observa-se, em muitos casos, que a escolha dos segmentos que representam os usuários acaba por não representar uma parcela significativa da população (WENDHAUSEN; CAPONI, 2002). No mesmo sentido, Avritzer (2007) questiona até que ponto esta redução a certas organizações de segmentos da sociedade civil de fato representa o conjunto de cidadãos.

Este formato de escolha da representação da sociedade civil nos conselhos de saúde tem favorecido setores com maior poder socioeconômico (LUCHMANN, 2008), deixando de atender as necessidades de grande parte da população (YOUNG, 2006). Shimizu et al. (2013) chamam atenção que setores excluídos da sociedade sem poder de organização associativa ou política, em alguns casos, podem abrir espaço para organizações sociais da classe média (Rotary, Lions, Maçonaria), comprometendo a representação da sociedade civil, especialmente dos que dependem e utilizam o sistema público de saúde. 
Sipioni e Silva (2015) constaram em pesquisa realizada em CMS que a representação da sociedade civil era composta por entidades extremamente desarticuladas e que não possuíam influência ou atuação na área da saúde e que sua participação foi a partir de convite da secretaria municipal de saúde.

Uma das formas de ampliar os canais de participação social com representação que considere toda a população é a criação de conselhos locais de saúde, que funcionariam como braços do CMS (SOUZA; KRÜGER, 2010).

\subsection{REPRESENTATIVIDADE}

Representatividade é o ato de representar, que se alcança por meio de um movimento de informação e prestação de contas, ficando claro não apenas a responsabilidade do representante frente ao grupo de seus representados, mas também o movimento contrário, sendo corresponsabilidade dos representados subsidiar seus representantes com informações, opiniões e discussões realizadas naquele grupo e também de cobrá-lo quanto à sua atuação (SERAFIN; SANTOS, 2008).

Para garantia da representatividade, tanto o processo de escolha do representante quanto sua afinidade com o tema (saúde e necessidades) são pressupostos essenciais para sua legitimidade e consequente efetiva participação (MAGNAGNAGNO; DOMBROWSKI, 2011). A baixa importância dada ao processo de escolha dos representantes é fator limitante da representatividade e consequente legitimidade do ato de representar um grupo (WENDHAUSEN; BARBOSA; BORBA, 2006).

Além disso, ainda existe a necessidade de que o representante leve a perspectiva dos representados, pois também existem conflitos de interesse que envolvem a vida social do representante (HOROCHOVSKI; MEIRELLES, 2007). Os atores políticos, ao decidirem pela representação de segmentos, podem ter objetivos de autopromoção, controle do poder burocrático ou, ainda, de sentimento coletivo e realização de cidadania (MILANI, 2008).

O que ocorre é que existe reprodução do sistema de representação participativa que segue os moldes da representação tradicional eleitoral, com desconexão entre representantes e representados, sem garantia da expressão coletiva (MENDES, 2007).

Ainda que exista discussão entre representante e representados, existem diferenças no interior de cada segmento as quais necessitam ser conciliadas. Além disso, mesmo o representante tendo opinião própria, ele deve expressar a opinião do coletivo, considerando o que foi discutido e pactuado e, posteriormente, devolver ao coletivo o que foi discutido na instância colegiada (SERAFIM; SANTOS, 2008). O representante também deve ser sensível às necessidades trazidas por outros segmentos da sociedade civil e outros setores de representação, pois a democracia reside no direito de todos os cidadãos e não numa disputa de segmentos (SERAFIM; SANTOS, 2008).

Segundo Van Stralen et al. (2006) e Cotta, Cazal e Martins (2010), a maioria dos representantes comparece às reuniões do colegiado sem consultar seus pares, expondo apenas seu ponto de vista e sem devolução ao grupo posterior das decisões tomadas nas reuniões. Assim, a baixa representatividade desses líderes revela um elemento essencial para a compreensão da fragilidade da participação social.

Estudo realizado por Gohn (2002) aponta que, na maioria dos municípios, os conselheiros da sociedade civil utilizam seu cargo em benefício político próprio, sem atender às reivindicações 
da população. Para diminuir a influência político-partidária e interesses alheios ao coletivo, a sugestão é que a indicação e escolha de conselheiros da sociedade civil sejam feitas em assembleias abertas, desenvolvendo assim o potencial democrático participativo (SHIMIZU et al., 2013).

Estudo realizado por Sipioni e Silva (2015) demonstra que os conselheiros usuários justificam a ausência de diálogo dentro do segmento, pela autonomia conferida pelos seus pares, experiência na representação ou por subestimação da opinião dos outros. O estudo revela ainda que a mesa diretora do conselho envia a pauta pouco antes da reunião, dificultando a discussão dentro do segmento.

Segundo Santos, Azevedo e Ribeiro (2004), nas reuniões mensais dos conselhos circulam informações e análises interessantes e várias vezes importantíssimas sobre a política de saúde e SUS, justificando novamente a importância da comunicação do representante com seus representados.

Existe a necessidade de institucionalizar uma cultura de representação que considere mecanismos formais de discussão e prestação de contas para garantia da legitimidade do processo de participação social (SIPIONI; SILVA, 2015).

De acordo também com Presoto e Westphal (2005), democratizar as informações e permitir sua avaliação por parte dos usuários seria colocá-los no centro do processo numa relação de corresponsabilidade. Mas, para que isso aconteça, torna-se necessária a existência de canais de participação desobstruídos e fluxo constante de informações, que favoreçam a participação ativa, representativa e autônoma, e que propiciem o crescimento das pessoas e das organizações coletivas.

Como artifício para disseminar essas informações, Assis e Villa (2003) sugerem a importância de implantar instrumentos que possibilitem a democratização da informação, como cartilhas, boletins informativos, jornais, entre outros, garantindo maior visibilidade dos conselhos e levando as informações necessárias a um número maior de pessoas.

A representatividade pode ser potencializada e legitimada mediante alguns mecanismos: realização de reuniões periódicas dentro do segmento para discussão, tomada de decisão e prestação de contas; disseminação de informações como suporte para discussão e tomada de decisões; oficialização de posição do segmento frente aos órgãos públicos por meio de documento protocolar; respeito por parte do representante das decisões discutidas no seu segmento (SERAFIM; SANTOS, 2008).

\section{CONSIDERAÇÕES FINAIS}

O modelo de democracia participativa representa importante instrumento de controle da sociedade civil na formulação, no acompanhamento e na prestação de contas das ações do Estado no setor saúde.

Porém a revisão dos trabalhos publicados demonstrou fragilidades relacionadas ao entendimento sobre participação, fruto da falta de empoderamento sobre o processo democrático e ainda sobre o próprio setor saúde. Estes aspectos já de início prejudicam todo o processo de construção de participação popular e consequente autonomia por parte da sociedade civil.

Além disso, a forma de organização de escolha de segmentos para representação da sociedade civil nos CMS não abrange o conjunto de cidadãos, especialmente os que mais necessitam ser ouvidos. 
Outra limitação encontrada internamente nos segmentos da sociedade civil está relacionada à representatividade, em que o processo de escolha do representante e ainda os mecanismos de discussão e devolução são bastante incipientes, o que deslegitima todo o processo de democracia participativa.

A materialização da democracia participativa nos conselhos gestores depende de vários aspectos que devem ser sincrônicos, como se demonstra na Figura 1, pois a falta ou a limitação de um deles prejudica todo o processo. Desta forma, torna-se condição fundamental: a clareza sobre o ato de participar numa perspectiva coletiva; o empoderamento comunitário, especialmente no que se refere à cidadania e à saúde; a reorganização na escolha dos segmentos representativos da sociedade civil que contemple toda a população; e mecanismos que garantam a legitimidade na representatividade dos segmentos.

Figura 1: Aspectos relacionados à participação social na saúde

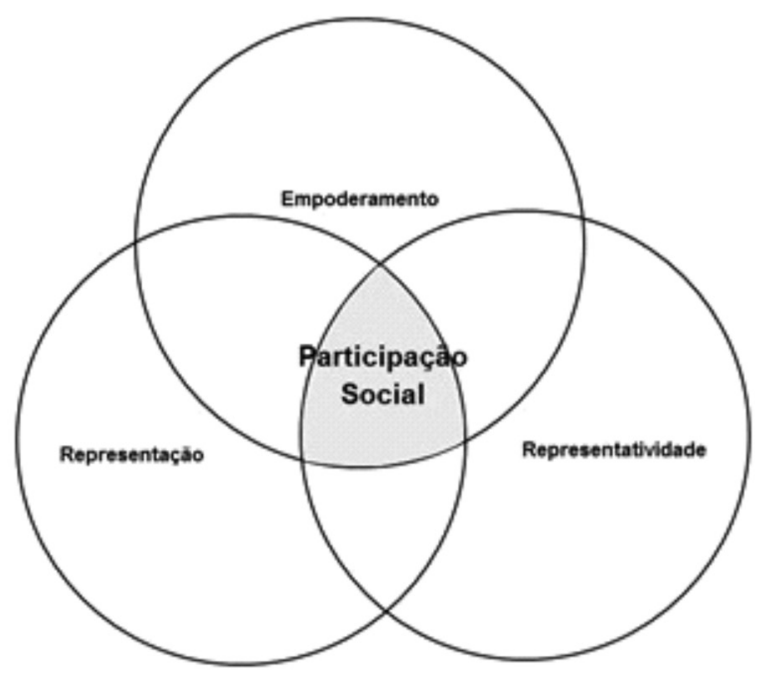

Fonte: Elaborada pelos autores.

Neste sentido, é necessário ampliar os canais de publicização das informações sobre saúde e sobre as decisões do setor saúde, como forma de empoderamento coletivo.

Além disso, uma forma de garantir a legítima representação da sociedade civil nos CMS é fortalecer a formação de conselhos locais como representação da sociedade civil nos CMS.

A representação dos vários segmentos da sociedade como associações de pessoas com problemas crônicos ou deficiências, associações de moradores, movimentos sociais e outras entidades, bem como as formas não organizadas, estariam representadas nos conselhos locais de saúde, de acordo com a organização de cada território. Desta forma, o CMS deixaria de ser palco de disputas de segmentos e projetos fragmentados na direção de um bem social comum, pois os conselhos locais representariam um agregado de necessidades de um território, e o CMS, o conjunto de necessidades do município.

Em relação à representatividade, é necessária a construção de mecanismos que garantam sua legitimidade. Os mecanismos de escolha do representante devem considerar a vontade coletiva das comunidades, com grande publicidade para o processo. Além disso, devem ser desenvolvidas formas institucionalizadas que garantam discussão prévia e devolução do representante para os representados, registradas por meio de atas das reuniões dos conselhos locais. 
O desenvolvimento das formas de representação e das formas de representatividade também auxiliam para o processo de empoderamento comunitário e esse conjunto de situações pode também garantir a legitimidade e o próprio desenvolvimento da participação social como expressão da vontade da sociedade civil na construção e na condução das políticas públicas de saúde.

\section{REFERÊNCIAS}

ABERS, R. N. Inventing Local Democracy: Grassroots Politics in Brazil. Boulder: Lynne Rienner Publishers, 2001.

ACIOLI, S. Participação social na saúde: revisitando sentidos, reafirmando propostas. In: PINHEIRO, R,; MATTOS, R. A. (Org.). Construção social da demanda: direito à saúde, trabalho em equipe, participação e espaços públicos. Rio de Janeiro: IMS/ UERJ, Abrasco, 2005.

ASSIS, M. M. A.; VILLA, T. C. S. O Controle social e a democratização da informação: um processo em construção. Revista Latino-Americana de Enfermagem, Ribeirão Preto, v. 11, n.3, p. 376-382, 2003.

AVRITZER, L. Sociedade civil, instituições participativas e representação: da autorização à legitimação da ação. Dados, Rio de Janeiro, v. 50, n.3, p. 443-464, 2007.

BAQUERO, R. V. A. Empoderamento: instrumento de emancipação social? - uma discussão conceitual. Revista Debates. Porto Alegre, v.6, n.1, p. 173-187, 2012.

BRASIL. $8^{\text {a }}$ Conferência Nacional de saúde. Tema II - Reformulação do Sistema Nacional de Saúde, Subtema C - Participação Social em Saúde. Brasília, 1986.

BRASIL. Conselho Nacional de Saúde. Resolução no 453, de 10 de maio de 2012. Brasília: Diário Oficial da União, 10 maio de 2012, 2012.

BRASIL. Constituição da República Federativa do Brasil. Brasília: Senado Federal, 1988.

BRASIL. Lei 8.142, de 28 de dezembro de 1990. Brasília: Diário Oficial da República Federativa do Brasil, n. 249, de 31 dezembro de 1990, 1990.

BROOME, M. E. Integrative literature reviews for the development of concepts. In: RODGERS B. L.; KNAFL, K. A. (editors). Concept development in nursing: foundations, techniques and applications. Philadelphia (USA): W.B Saunders Company, 2000.

BUSS, P. M. Promoção da saúde e qualidade de vida. Ciência \& Saúde Coletiva, Rio de Janeiro, v. 5, n.1, p. $163-177,2000$.

CARVALHO, G. I.; SANTOS, L. Das formas de controle social sobre ações e os serviços de saúde. Brasília: Ministério da Saúde, 1992.

COELHO, V. S. P. A democratização dos conselhos de saúde: o paradoxo de atrair não aliados. Novos estudos - CEBRAP, São Paulo, n. 78, p. 77-92, 2007.

CONSELHO NACIONAL DOS SECRETÁRIOS MUNICIPAIS DE SAÚDE. Participação social no SUS: olhar da gestão municipal. Brasília: CONASEMS, 2009.

CORREIA, M. V. C. Desafios para o controle social: subsídios para a capacitação de conselheiros de saúde. Rio de Janeiro: FIOCRUZ, 2005.

COTTA, R. M. M.; CAZAL, M. M.; MARTins, P. C. Conselho Municipal de Saúde: (re)pensando a 
lacuna entre o formato institucional e o espaço de participação social. Ciência \& Saúde Coletiva, Rio de Janeiro, v. 15, n.5, p. 2437-2445, 2010.

CUNILL GRAU, N. Balance de la participación ciudadana em lãs políticas sociales. Propuesta de um marco analítico. In: ZICCARDI, A. (Org.). Participación ciudadana y políticas sociales del âmbito local. México (DF): IIS/Comecso/Indesol, 2004.

FREIRE, P.; SHOR, I. Medo e ousadia - o cotidiano do professor. Rio de Janeiro: Paz e Terra, 1986.

FREIRE, P. Pedagogia do oprimido. São Paulo: Paz e Terra, 2004.

GOHN, M. G. Papel dos conselhos gestores na gestão pública. Informativo Cepam, São Paulo, v. 1, n.3, p. 7-15, 2002.

HOROCHOVSKI, R.R.; MEIRELLES, G. Problematizando o conceito de empoderamento. In: II Seminário Nacional Movimentos Sociais, Participação e Democracia, 2007, Florianópolis. Anais... Disponível em: <http://www.sociologia.ufsc.br/npms/rodrigo_horochovski_meirelles.pdf>. Acesso em: 09 mar. 2017.

KLEBA, M. E.; WENDAUSEN, A. Empoderamento: processo de fortalecimento dos sujeitos nos espaços de participação social e democratização política. Saúde e Sociedade, São Paulo, v.18, n.4, p. 733-743, 2009.

LUCHMANN, L. H. H. Participação e representação nos Conselhos Gestores e no Orçamento Participativo. Caderno CRH, Salvador, v. 21, n.52, p. 87-97, 2008.

MAGNAGNAGNO, J.K.; DOMBROWSKI, O. A legitimidade da representação na democracia participativa. Anais do Seminário nacional da pós-graduação em ciências sociais. Vitória, v.1, n.1, 2011.

MARTins, P. C. et al. Conselhos de Saúde e a Participação Social no Brasil: Matizes da Utopia. Physis Revista de Saúde Coletiva, Rio de Janeiro, v. 18, n.1, p. 105-121, 2008.

MARTINS, P. C. et al. Democracia e empoderamento no contexto da promoção da saúde: possibilidades e desafios apresentados ao programa de saúde da família. Physis - Revista de Saúde Coletiva, Rio de Janeiro, v.19, n. 3, p. 679-694, 2009.

MENDES, D. C. V. R. Representação política e participação: reflexões sobre o déficit democrático. Revista Katál, Florianópolis, v. 10, n.2, p. 143-153, 2007.

MILANI, C. R. S. O princípio da participação social na gestão de políticas públicas locais: uma análise de experiências latino-americanas e europeias. RAP, Rio de Janeiro, v. 42, n. 3, p. 551-79, 2008.

MINAYO, M. C. S. O desafio do conhecimento: pesquisa qualitativa em saúde. São Paulo: Hucitec, 2007.

MOREIRA, I. A.; HEIDRICH, A. V. Participação social na saúde: limites e possibilidades de controle social em tempo de reforma do Estado. Sociedade em debate, Pelotas, v. 18, n. 2, p. 107-119, 2012.

NAVARRETE, M. V. et al. Visión de los diferentes agentes sociales sobre la participación social en el sistema de salud en el nordeste de Brasil: una aproximación cualitativa. Revista Espanhola de la Salud Pública, Madri, v. 76, n.5, p. 585-594, 2003.

PATEMANN, C. Participação e teoria democrática. Rio de Janeiro: Paz e Terra; 1992.

POLIT D. F.; BECK C. T. Using research in evidence-based nursing practice. In: POLIT, D. F.; BECK, C.T. (editors). Essentials of nursing research. Methods, appraisal and utilization. Philadelphia (USA): Lippincott Williams \& Wilkins, 2006. 
POZZONI, B. Citizen participation and deliberation in Brazil. Dissertação de mestrado apresentada ao Institute of Development Studies. University of Sussex, 2002.

PRESOTO, L. H.; WESTPHAL, M. F. A participação social na atuação dos conselhos municipais de Bertioga - SP. Saúde e Sociedade, São Paulo, v. 14, n.1, p. 68-77, 2005.

SAntos, J. A. O.; AZEVEDO, S.; RIBEIRO, L. C. Q. Democracia e gestão local: a experiência dos conselhos municipais no Brasil. In: SANTOS JÚNIOR, A. O.; RIBEIRO, L. C. Q.; AZEVEDO, S. (Org.). Governança democrática e poder local: a experiência dos conselhos municipais no Brasil. Rio de Janeiro: Revan, 2004.

SERAFIM, L.; SANTOS, A. Representação e representatividade nos espaços de participação cidadã. Adaptação da publicação "Enfrentando os desafios da representação em espaços participativos". São Paulo: CEBRAP - IDS, 2008.

SHIMIZU, H. E. et al. Representações sociais dos conselheiros municipais acerca do controle social em saúde no SUS. Ciência \& Saúde Coletiva, Rio de Janeiro, v. 18, n.8, p. 2275-2284, 2013.

SILVA, V. R. Controle Social de políticas públicas: uma reflexão sobre os resultados da pesquisa. In: PEDRINI, D. M. et al. (Org.). Controle Social de Políticas Públicas: caminhos, descobertas e desafios. São Paulo: Paulus, 2007.

SIPIONI, M. E.; SILVA, M. Z. Reflexões e interpretações sobre a participação e a representação em conselhos gestores de políticas públicas. Revista de sociologia e política, Curitiba, v. 21, n.46, p. 147$158,2013$.

SIPIONI, M. E.; SILVA, M.Z. Democracia e saúde: a prestação de contas como legitimadora da representação no conselho municipal de saúde de Vitória (ES). Revista Saúde e Debate, Rio de Janeiro, v. 39, n.104, p. 197-209, 2015.

SOUZA, A. V.; KRÜGER, T. R. Participação Social no SUS: Proposições das Conferências sobre o Conselho Local de Saúde. Revista de Saúde Pública de Santa Catarina, Florianópolis, v. 3, n. 1, 2010.

SOUZA, M. T.; SILVA, M. D.; CARVALHO, R. Revisão integrativa: o que é e como fazer. Einstein, São Paulo, v. 8(1-pt 1), p 102-106, 2010.

WENDHAUSEN, A; CAPONI, S. O diálogo e a participação em um conselho de saúde em Santa Catarina, Brasil. Cadernos de Saúde Pública, Rio de Janeiro, v. 18(6), p. 1621-1628, 2002.

Wendhausen, A. L. P.; BARBOSA, T. M.; BORBA, M. C. Empoderamento e recursos para a participação em conselhos gestores. Saúde e Sociedade, São Paulo, v. 15, n.3, p. 131-144, 2006.

WENDHAUSEN A.; CARDOSO, S. M. Processo decisório e Conselhos Gestores de Saúde: aproximações teóricas. Revista Brasileira de Enfermagem, Brasília, v. 60, n.5, p. 579-84, 2007.

VAN STRALEN, C. J. et al. Conselhos de Saúde: efetividade do controle social em municípios de Goiás e Mato Grosso do Sul. Ciência e Saúde Coletiva, Rio de Janeiro, v. 11, n.3, p. 62 1-632, 2006.

VÁZQUEZ, M. L. et al. Los procesos de reforma y la participación social en salud en América Latina. Gaceta Sanitaria, n. 16, p. 30-38, 2002.

YOUNG, I. M. Representação política, identidade e minorias. Lua Nova, São Paulo, n. 67, p. 139-190, 2006. 